\title{
O uso variável dos clíticos acusativos para referenciar o interlocutor
}

\author{
The variable use of acusative clitics to reference the interlocutor
}

\begin{abstract}
Resumo: Este trabalho traz uma análise sobre o uso variável das formas clíticas te e lhe como estratégias de referência à segunda pessoa do singular, no Português do Brasil (PB) e, para tal, respaldou-se em dados de fala oral, coletados do município baiano de Feira de Santana, no interior do estado. Dentre os resultados, destacam-se os grupos de fatores faixa etária e escolaridade, sendo os falantes a partir de 65 anos (faixa III) os que mais fazem uso do clítico lhe para referenciarem o interlocutor. A escolaridade dos informantes confirma a hipótese de que os falantes com menor escolaridade fazem maior uso do clítico em sua forma não canônica, referenciando a segunda pessoa. Dessa maneira, este estudo agrega dados sobre a investigação de lhe como objeto direto de segunda pessoa em Feira de Santana, assim como em outras variedades do PB.
\end{abstract}

Palavras-chave: Sistema pronominal. Segunda pessoa. Português brasileiro.

\begin{abstract}
This work presents an analysis on the variable use of the clitic forms te and lhe (you) as reference strategies to the second person singular in the Brazilian Portuguese (PB) and, for this, it was based on oral speech data, collected from the municipality of Bahia of Feira de Santana, in the interior of the state. Among the results, the groups of factors age group and schooling stand out, being the speakers from 65 years (range III) the ones that make use of the clitic lhe (you) one more to reference the interlocutor. The schooling of the informants confirms the hypothesis that the speakers with less schooling make greater use of the clitic in its non canonical form, referring to the second person. In this way, this study aggregates data about the investigation of lhe (you) as direct object of second person in Feira de Santana, as well as in other PB varieties.
\end{abstract}

Keywords: Pronominal system. Second person. Brazilian portuguese.

\section{INTRODUÇÃO}

O objetivo deste trabalho é mostrar o uso dos pronomes oblíquos te e the como formas alternadas de referência ao interlocutor, propondo uma correlação do uso dessas formas com a reorganização do quadro pronominal do Português do Brasil (PB). Para tal reflexão, parte-se da amostra de fala espontânea constante no banco de dados do projeto de pesquisa $A$ lingua portuguesa falada no semiárido baiano, composto por um total de 72 amostras de fala, somados aos dados dos inquieritos realizados por Silva (2016), em sua dissertação de mestrado.

*Mestre em Estudos Linguísticos (UEFS), atualmente é aluna do doutorado em Língua Portuguesa na Universidade Federal do Rio de Janeiro. E-mail: igorengcomp@gmail.com. 
A comunidade de fala observada é o município baiano de Feira de Santana, interior do estado, no qual existe a marca dialetal de $t u$, pronome pessoal, como referencia de segunda pessoa (tu está), sem a marcação da flexão canônica (tu estas). Os resultados maiores, apontados por (Silva, 2016), indicaram a alternância de ambas as formas no município feirense e foram paralelamente comparados com os dados da capital baiana (ALMEIDA, 2009), mostrando o uso generalizado das formas pelo estado baiano. O intuito do atual artigo é discorrer sobre o uso variável das formas oblíquos supramencionadas, chamando a atenção ao uso inovador de lhe como estratégia de referencia a segunda pessoa, desapontando o que prescreve a tradição gramatical sobre o emprego desse clítico em posição de referencia à terceira pessoa.

Mesmo ciente da varianção no emprego de the como objeto direto (OD) na fala baiana (ALMEIDA, 2009, 2014; SILVA, 2016), vale mencionar que não é o foco deste artigo explanar sobre a alternância de sua função sintática, mas observar como tais clíticos atuam em correlação de referencia ao interlocutor do discurso, estabelecendo relação dessa estratégia de uso à reorganização do sistema pronominal do $\mathrm{PB}$, condicionada, sobretudo, após a inserção de você no sistema (LOPES E CAVALCANTE, 2011).

Dessa maneira, este artigo segue organizado da seguinte forma: a seção 1 há uma descrição breve sobre o fenômeno linguístico, partindo da prescrição gramatical clássica, seguindo para a subseção 1.2, na qual se traça um panorama geral sobre o fenômeno, desde os estudos pioneiros, iniciados no século XX (AMARAL, 1920 [1976]; NASCENTES, 1922; MARROQUIM, 1934 [1996]), aos estudos mais contemporâneos, desenvolidos na capital e interiores da Bahia (ALMEIDA, 2009, 2014; SILVA, 2016) e em outras variedades do PB (OLIVEIRA, 2003; LUCAS, 2008). A subseção 1.3 expõe o corpus e a metodologia utilizada na coleta e análise dos dados. A seção 2 explana sobre as observações e análises dos dados, apontando os principais grupos de fatores relevantes ao fenômeno linguístico em questão. Por fim, as considerações finais, na seção 3.

\section{DESCRIÇÃO DO OBJETO}

Segundo a Gramática Tradicional (GT), os pronomes oblíquos devem ser empregados em função de objeto direto (OD) ou indireto (OI), dependendo da transitividade do verbo, sendo objeto direto para os verbos transitivos diretos e objeto indireto para os verbos de transitividade indireta. Essa regra gramatical vale para os pronomes pessoais de primeira e segunda pessoa, sendo complementos da primeira e segunda pessoa os pronomes oblíquos me, te, nos, vos, podendo representar tanto o OD como também o OI dos verbos. Contudo, para a terceira pessoa a GT não dita dessa forma os complementos verbais, sendo especificadas as formas $0, a$, os, as para representar o objeto direto e lhe, lhes como formas representativas de objeto indireto.

$\mathrm{Na}$ tradição do latim, as categorias gramaticais eram divididas em casos e, neste contexto, a categoria que demarcava o objeto direto que conhecemos hoje em português era o acusativo, designado para indicar o ser afetado pela ação; e o objeto indireto era 
correspondente ao dativo, para indicar o beneficiário ou destinatário da ação. No período de transição do Latim ao Português, o sistema de 'casos' latinos sofreu mutação para uma sintaxe de 'ordem', no português.

Decorrente dessa passagem e transição de uma língua a outra, o português teve que recorrer às preposições a fim de demarcar seu objeto indireto nas sentenças, visto que os valores dos casos latinos não existiam mais. Assim, todo complemento verbal regido de preposição independentemente de indicar o ser a que se destina a ação ou em cujo proveito ou prejuízo se realiza, deve ser incluído na categoria de objeto indireto.

Voltando-se para o sistema pronominal, nota-se que, após a fixação dos pronomes você e, posteriormente, a gente, sucederam-se várias alterações morfossintáticas no quadro do PB. Com base nos dados de pesquisas sobre este assunto, têm sido evidenciados resultados inovadores, tanto no fato do uso dos pronomes pessoais do caso reto, como também do emprego dos pronomes oblíquos. Segundo Almeida (2009), esses estudos sugerem a reorganização do quadro pronominal não somente na primeira e segunda pessoa, em menor ou maior grau, mas em todas as pessoas do discurso. Contudo, as pesquisas apontam para um índice de maior mudança no nível de terceira pessoa.

Desta realidade sobre o sistema pronominal do $\mathrm{PB}$, vários trabalhos têm se dedicado em busca de um melhor quadro representativo dessa categoria gramatical. Contudo, ainda não se chegou a um sistema de completo mapeamento descritivo da atual situação da classe gramatical em questão. Mesmo assim, considerou-se o quadro de Ramos (1999, p. 9), não como o mais completo, porém, como o que melhor representa a realidade do uso dos pronomes no português falado no Brasil, divergindo dos padrões ditados pela canônica gramática normativa da língua portuguesa de base europeia.

Figura 01: Distribuição dos pronomes pessoais em função de sujeito e complementos nas variedades do PB

\begin{tabular}{|c|c|c|c|}
\hline \multirow[b]{2}{*}{ Pes/número } & \multicolumn{3}{|c|}{ Função } \\
\hline & Sujeito & Objeto direto & Objeto indireto \\
\hline $1^{\mathrm{a}} \operatorname{sing}$ & eu & $\mathrm{Me} / \mathrm{eu}$ & a/para mim/eu, me \\
\hline \multirow{2}{*}{$2^{\mathrm{a}} \operatorname{sing}{ }^{*}$} & $\begin{array}{c}\text { tu } \\
\text { você }\end{array}$ & $\begin{array}{c}\text { te, tu } \\
\text { lhe, você }\end{array}$ & a/para ti/te/tu/lhe, a/para você \\
\hline & você & você, te, lhe & a/para você, te, lhe \\
\hline $3^{\mathrm{a}}$ sing & ele/ela & o, ele/ ela, lhe & a/para ele/ela, the \\
\hline $1^{\mathrm{a}}$ plural & $\begin{array}{l}\text { nós } \\
\text { a gente }\end{array}$ & $\begin{array}{l}\text { nos, nós } \\
\text { a gente }\end{array}$ & $\begin{array}{l}\text { a/para nós, nos } \\
\text { para a gente }\end{array}$ \\
\hline $2^{\mathrm{a}}$ plural & vocês & lhes, vocês & lhes, a/para vocês \\
\hline $3^{\mathrm{a}}$ plural & eles (elas) & os, eles/elas, thes & a/para eles/ elas, lhes \\
\hline
\end{tabular}

Fonte: Ramos (1999, p. 9). 
Tratando-se disso, é no paradigma de terceira pessoa que os processos de variação e mudança têm-se desenvolvido mais, dentre as quais vale citar o 'desuso' das formas ${ }^{1}$ de acusativo (a, o, as, os) e das formas dativas (lhe, lhes), resultando em usos inovadores em suas funções, visto que derivam em empregos que diferem das prescrições gramaticais da língua portuguesa.

No tratamento do clítico pronominal lhe, especificamente, a tradição gramatical prescreve que este oblíquo deve surgir nas sentenças em posição de objeto indireto e, diante dos exemplos apontados pelas gramáticas normativas, este é um clítico de argumento selecionado. Contudo, algumas pesquisas quantitativas foram feitas em várias regiões do País (ALMEIDA, 2009; 2014; LUCAS, 2008; OLIVEIRA, 2003, dentre outras), nas quais se atestam questionamentos empíricos sobre o emprego do the no português falado no Brasil.

\subsection{ESTUDOS SOBRE O USO VARIÁVEL DO LHE NO PB: ALGUNS RELATOS}

Uma das motivações para a investigação sobre as origens do PB parte da notável disparidade entre esse e o PE, trazido para o país como língua falada pelos colonizadores, no século XVI. Considerando essa diferença entre as duas variedades da língua portuguesa, estudos de dialetólogos e especialistas, como Amaral (1920 [1976]), Marroquim (1934 [1996]) e Nascentes (1922), dentre outros, ainda que menos empíricos, já mostravam aspectos gerais sobre as peculiaridades do PB.

Ainda em décadas mais recentes, outros estudos linguísticos se debruçaram na tentativa de buscar as raízes do PB (MATTOS E SILVA, 2001, 2002, 2008 dentre outros), partindo das observações sobre as suas características, do ponto de vista léxicosemântico, fonético-fonológico e morfossintático, buscando explicações baseadas não apenas em questões imanentes, mas, também, em aspectos sócio-históricos subjacentes.

Respaldando-se em estudos de cunho sócio-histórico (TARALLO, 1993; GALVES, 1987, 1993; MIRA MATEUS, 2006, dentre outros) levantaram um vasto acervo de teses que descrevem e analisam fenômenos linguísticos em diferentes variedades do português, a fim de levantar hipóteses e encontrar respostas possíveis sobre as questões que envolvem as suas origens e formação. Em especial, hipóteses que consideram o cenário de multilinguísmo no qual se encontrou o Brasil no início da sua formação.

Sobre o uso variável do pronome oblíquo the já se evidenciam ressalvas indulgentes em observações pioneiras desenvolvidas no início do século XX, por Amadeu Amaral e Antenor Nascentes, com $O$ dialeto Caipira e O linguajar carioca, respectivamente, como, também, nos estudos sobre A língua do nordeste: Alagoas $e$ Pernambuco, de Mário Marroquim.

Com base nos estudos pioneiros sobre o PB, nota-se que há uma vasta gama de fenômenos analisados em amostras sincrônicas, atualmente, que já foram apontados em

\footnotetext{
1 Os termos acusativo e dativo aqui utilizados correspondem ao objeto direto (OD) e ao objeto indireto (OI), respectivamente.
} 
estudos anteriores. A preocupação com o linguajar falado nas diversas regiões do país direciona uma pesquisa linguística que aflora, mais estritamente, em obras, como $O$ dialeto Caipira (1920 [1976]), O linguajar carioca (1922) e A lingua do nordeste: Alagoas e Pernambuco (1934 [1996]).

Autores como Amadeu Amaral, Antenor Nascentes e Mário Marroquim expuseram alguns relatos pertinentes sobre as diferentes formas de falar o português, em diferentes regiões. As observações desenvolvidas por esses estudiosos, ainda que não fossem de cunho investigativo mais específico, como nos dias atuais, deram margem à análise e comparação das pesquisas sincrônicas, desenvolvidas sobre o que se constitui o português falado no Brasil.

Em especial, no que respeita ao pronome oblíquo lhe, a gramática tradicional dita regra para o seu uso como objeto indireto, correspondendo ao dativo latino. Contudo, nota-se variação no uso desse oblíquo, também, como objeto direto, referindo-se ao antigo acusativo latino. Sobre essa alternância, além dos autores anteriormente citados, pesquisas sincrônicas contemporâneas, de cunho variacionista, desenvolvidas sobre a capital baiana e interiores, apontaram para a existência da variação, não apenas pelos menos escolarizados, como, também, por falantes de escolaridade superior (ALMEIDA, 2009, 2014; SILVA, 2016).

Sobre tal fenômeno, Amaral (1920 [1976]) faz alusão a utilização do pronome para referenciar a segunda pessoa (com quem se fala), não sendo marcado como pronome de terceira pessoa (de quem se fala), como prescreve a gramática normativa. Conforme o que diz o autor, para se referir a terceira pessoa, o "caipira" usa a expressão para ele, como complemento, em oposição à forma canônica.

Além disso, os estudos pioneiros que já falavam sobre o fenômeno linguístico em questão, Marroquim (1934 [1996]) aborda aspectos linguísticos sobre o português falado nos estados de Alagoas e Pernambuco, região do nordeste brasileiro, dentre os quais comenta, também, sobre o uso variável do lhe como acusativo.

A respeito do caso dos oblíquos, o autor explana sobre o desuso das formas canônicas 0 , $a$, os, as, para complementos verbais. Em particular o lhe já era observado em sua função de complemento direto. A propósito dessa alternância, Nascentes (1922, p. 67) comenta sobre a fala dos cariocas:

Assim como os pronomes me, te (e também nos, nós) exercem as funções de objeto direto e indireto, por analogia, 'the' que exerce só a de indireto [segundo a tradição da gramática normativa], por terminar do mesmo modo que os outros, passou também a exercer a de objeto direto [grifos meus].

Observando o uso do oblíquo the como objeto direto e indireto, acusativo e dativo, respectivamente, Mário Marroquim comenta sobre a semelhança no uso desse pronome como complemento direto, tanto no Rio de Janeiro, como no nordeste do Brasil. A propósito da variante linguística em voga, o autor fala sobre o fator escolaridade, apontando que tal alternância de uso ocorre tanto pelos menos escolarizados, como, também, pelos de escolaridade superior. A dualidade ocorre quando os oblíquos $o$ e lhe são empregados, fazendo referência para a terceira pessoa e 
segunda pessoa, ao mesmo tempo. Tal uso variável também é observado no português falado em Feira de Santana, conforme vem apontando os estudos desenvolvidos por Silva (2016).

No estudo sincrônico desenvolvido em Salvador, Almeida (2009) faz uma crítica ao conceito dogmático da gramática tradicional e aponta em seus dados que essa é uma ideia tradicional questionável. Em seu corpus, constituído de fala de 36 informantes, verificou-se um uso bastante equilibrado entre as variantes te e lhe, apontando que, na capital baiana, o clítico lhe alterna-se entre dativo e acusativo, ao contrário do que prescreve a Gramática Tradicional (ALMEIDA, 2009, p. 9). A autora encontrou 251 ocorrências de lhe e 247 de te. A faixa etária mostrou-se um fator importante para explicar a variação te e the, apontando para o fato de que há, na capital em questão, uma mudança em curso em direção à forma te, mais utilizada pelos jovens, faixa I (25 a 35 anos) e conservação do the como objeto acusativo de expressão à segunda pessoa pelos informantes da faixa III (65 a 75 anos). Já o fator sexo, apontou um maior índice de conservação do lhe como objeto direto pelos homens. A autora ressalta, também, que se trata de um trabalho pioneiro no que concerne ao objeto de estudo e que tal assunto não foi discutido exaustivamente.

Outro trabalho de dissertação de mestrado foi defendido na Universidade Federal de Brasília, em 2008, por Lucas, intitulado "Transitividade variável em verbos monotransitivos e o uso inovador do lhe no Português do Brasil" e buscou desenvolver seu estudo partindo da análise da sintaxe de complementação e pronominalização do $\mathrm{PB}$, mas especificamente a ocorrência dos complementos preposicionados em posição de complementos acusativos. O clítico the obteve, nesse estudo, uma dada atenção, na qual a autora apontou que "adicionalmente, demonstra-se que as mudanças no sistema pronominal do $\mathrm{PB}$, pelas quais passa e se caracteriza como sistema mais referencial em detrimento de um sistema casual conduzem a que o clítico seja mapeado também como clítico acusativo" (LUCAS, 2008, p. 12). Vale dizer que tal pesquisa contou com um aparato teórico diferente daquela, a saber, a Teoria Gerativa.

Alguns estudiosos fizeram mão da ideia de "uso inovador" do clítico the como objeto acusativo contudo, Oliveira (2003) justifica o emprego do lhe como O.D através da hipótese de recategorização. Para a autora, o desuso das formas $a$, o para representação do O.D no português falado no Brasil fez com que o lhe dativo assumisse uma função prototípica diferenciada. Sobre este questionamento, Oliveira (2003, p. 3) retoma a hipótese de Kato (1985) e diz:

[...] propõe a hipótese da distribuição harmônica entre os sistemas pronominais: se o objeto é tônico, tem-se o uso do genitivo dele, se o objeto é átono (me/te), tem-se o uso do possessivo (теи/teu). Podemos acrescentar: se temos o uso do possessivo seu (2a. pessoa), temos o uso de um pronome átono. Entretanto, o candidato mais provável, o clítico acusativo, com marcas de gênero, fere a hipótese da distribuição harmônica, pois se o pronome de 1a. pessoa (me) não é marcado quanto ao gênero, o pronome de 2a. pessoa também não o deve ser. Como lembra Pagotto (1993), os clíticos de 3a. pessoa diferem dos da 1a. e 2a. pessoas devido às marcas de concordância. $O$ clítico the não apresenta distinção de gênero e, portanto, passa a ser uma opção na língua. Resta explicar de que forma o clítico the passa a marcar pessoa. 
Com base nos estudos apontados aqui, percebe-se que a alternância linguística entre a representação do clítico the em posição de dativo e acusativo existe no português brasileiro e tem sido alvo de diversos trabalhos científicos de cunho variacionista, sobretudo. Dentre as alternâncias que ocorrem entre a língua portuguesa ditada pela gramática normativa e o emprego das formas pronominais na língua falada, destaca-se, neste artigo o uso dos clíticos te e the de referência a segunda pessoa do singular, na fala popular e culta do município baiano de Feira de Santana.

\subsection{CORPUS E METODOLOGIA UTILIZADOS}

Foram coletadas 60 entrevistas, sendo 36 de fala espontânea e 24 de inquéritos. As entrevistas de fala espontânea constituem parte do banco de dados do projeto de pesquisa $A$ lingua portuguesa falada no semiárido baiano $^{2}$, composto por um total de 72 amostras de fala espontâneas. A outra parte do corpus foi composta por inquérito, modelo produzido por Almeida (2009).

A comunidade baiana em estudo -Feira de Santana- foi escolhida com base no conhecimento precedente sobre o uso variável na representação do objeto de referência à segunda pessoa do singular, desde os estudos apontados por Silva e Almeida (2012, 2013). Tais estudos prévios despertaram o interesse à investigação do uso variável, não apenas desse clítico específico, mas, também, para outras formas estratégicas utilizadas pelo falante feirense, para referenciar o objeto acusativo e dativo de segunda pessoa.

A partir da transcrição ortográfica das entrevistas, foi realizado o mapeamento dos contextos previstos dos trechos de fala nos quais ocorrem alternância na representação dos clíticos em objetos diretos e indiretos de segunda pessoa. Os dados encontrados nos contextos foram codificados e rodados no GoldV arb $X$, programa computacional utilizado para análise sociolinguística quantitativa. O mapeamento desses contextos realizados buscou base nas predições da Sociolinguística Variacionista (LABOV, 1968 [2008], a fim de determinar suas características tanto linguísticas quanto pragmáticodiscursivas e socioculturais do uso dessa variante no município baiano de Feira de Santana.

\section{RESULTADOS E ANÁLISE DOS DADOS}

Das formas de representação do objeto direto e indireto de segunda pessoa no município baiano de Feira de Santana, os resultados destacaram os clíticos te e the como os frequentemente mais usados pelos falantes. A investigação desses clíticos buscou analisar os condicionamentos do uso, independentemente das suas funções sintáticas de $\mathrm{OD}$ e OI, visto que possuem caráter eminentemente sócio-discursivo, sendo ambos representativos da segunda pessoa do singular, na amostra aqui utilizada. A seguir, temse um gráfico representativo dessa distribuição.

\footnotetext{
${ }^{2}$ Ver detalhes sobre o projeto na nota 2.
} 
Gráfico 1: Distribuição das formas te e the de referência ao interlocutor, em Feira de Santana-BA

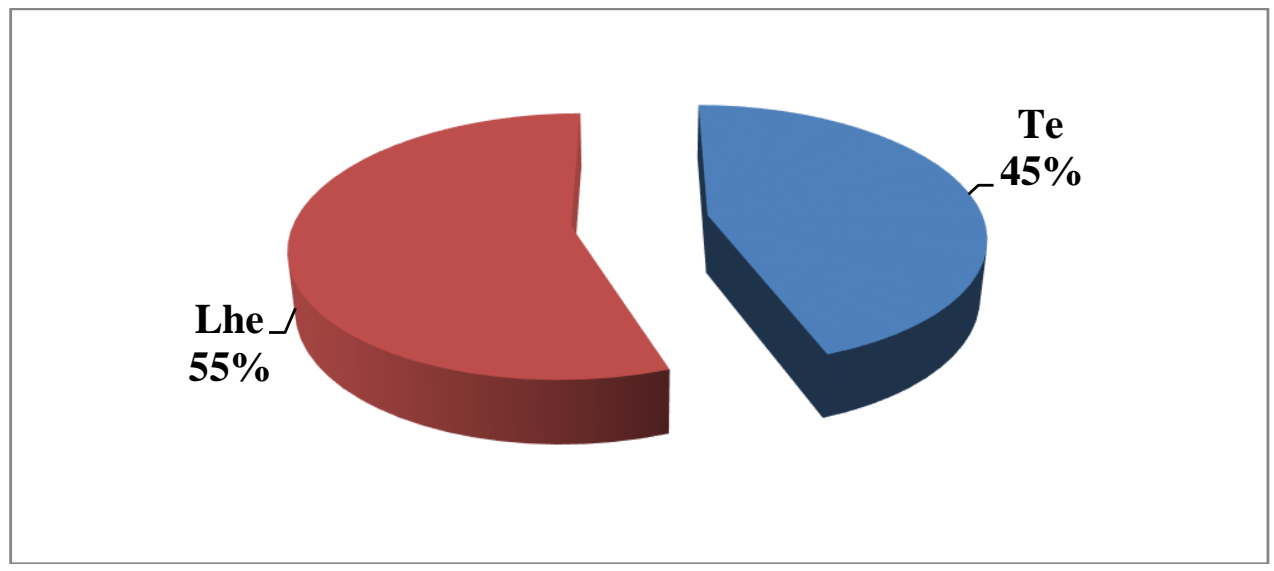

Fonte: Elaborado pela pesquisadora.

A distribuição apresentada no gráfico 01 confere resultados para o uso preferencial do oblíquo the, como objeto para referenciar a segunda pessoa, com 55\% (268/483) dos dados. Esse resultado assemelha-se aos resultados encontrados em estudos anteriores, desenvolvidos na mesma comunidade (SILVA; ALMEIDA, 2012, 2013) como, também, aos resultados a que chegou Almeida (2009), em análise da fala de Salvador.

$\mathrm{Na}$ tentativa de delimitar a variante linguística em análise, considera-se a hipótese de que o emprego do clítico the em posição de objeto ocorre, frequentemente, em um discurso mais dirigido ${ }^{3}$ de fala. Os informantes evitaram o preenchimento do objeto por um pronome mais inovador, como você e, ainda, a não preferência pelas formas canonizadas, $o / a$, prescritas pela tradição gramatical, marcadas por ausência de naturalidade, já em desuso no português brasileiro.

Sobre essa questão, Almeida (2011, p. 2402) retoma um exemplo pertinente da coluna do Dr. Sócrates, da revista Carta Capital, citada por Possenti (2002) "Já não era tão jovem, sua força de vontade estaria à prova por longos e cansativos meses. A delicada cirurgia exigiria mãos habilidosas para voltar a exercer, em plenas condições, o ofício que tanto the apaixona."

Porém, mesmo diante do exposto, a amostra de Feira de Santana destaca um equilíbrio no emprego de ambos os clíticos, pois a diferença entre os dois usos é de, apenas, $10 \%$. Assim, dos grupos de fatores estabelecidos como possíveis condicionantes da variação em estudo, o GoldV arb $X$ selecionou dois grupos, sendo: i) a faixa etária do informante e ii) grau de escolaridade. Vale salientar que ambos são de natureza extralinguística, conferindo a influência dos fatores sociais para explicação do fenômeno linguístico estudado. Com base nisso, explana-se nas subseções a apresentação dos

\footnotetext{
${ }^{3}$ Entende-se por dirigido os dados coletados através do inquérito, já mencionado (cf. seção 2).
} 
resultados e a análise feita mediante o número de ocorrências, seguida da frequência e dos pesos relativos correspondentes.

\subsection{A FAIXA ETÁRIA DOS INFORMANTES}

Esse fator foi distribuído em três idades distintas: 25 a 35 anos (faixa I), 45 a 55 anos (faixa II) e partir de 65 anos (faixa III). A distribuição dos resultados obtidos está exposta na tabela 01 .

Tabela 01: Atuação da variável faixa etária no uso dos clíticos te e lhe como representantes do objeto na forma de segunda pessoa. Significância: 0.008

\begin{tabular}{|c|c|c|c|c|c|c|}
\hline & \multicolumn{3}{|c|}{$\mathrm{Te}$} & \multicolumn{3}{|c|}{ Lhe } \\
\hline & Apl./Total & $\%$ & P.R & Apl./Total & $\%$ & P.R \\
\hline Faixa 3 & $(47 / 138)$ & $34,1 \%$ & 0.39 & $(91 / 138)$ & $65,9 \%$ & 0.60 \\
\hline Faixa 2 & $(90 / 173)$ & $52,0 \%$ & 0.57 & $(83 / 173)$ & $48,0 \%$ & 0.41 \\
\hline Faixa 1 & $(78 / 172)$ & $45,3 \%$ & 0.51 & $(94 / 172)$ & $54,7 \%$ & 0.50 \\
\hline TOTAL & $(215 / 483)$ & $44,5 \%$ & - & $(268 / 483)$ & $55,5 \%$ & - \\
\hline
\end{tabular}

Fonte: Elaborado pela pesquisadora.

Pelos resultados expostos na tabela 1 , nota-se a preferência pelo uso do clítico lhe como forma de referenciar o interlocutor, com 268/483 número de ocorrências e frequência de 55,5\%. Desse dado estatístico, os falantes que mais retêm o emprego do the são os com idade acima de 65 anos (faixa III), com frequência 65,9\% (91/138), cujo peso relativo é de 0.60. A hipótese inicial era que os indivíduos mais velhos usariam em maior proporção o clítico the para referenciar o interlocutor. Os resultados aqui apresentados comprovam a hipótese da fala dos mais velhos na comunidade é um dado que se assemelha a outras pesquisas de mesmo valor investigativo, sobre algumas variedades do PB, como por exemplo, Salvador e Santo Antônio de Jesus (ALMEIDA, 2009, 2014). A faixa II apresenta um equilíbrio no uso de ambas as formas, com frequência entre 52\% (90/173) para a forma te e 48\% (83/173) para o clítico lhe. Porém, comparando o uso do the entre a faixa II e os mais jovens, nota-se que os mais jovens preferencialmente fazem o uso desse clítico. Os pesos relativos 0.50 e 0.51 conferidos para os clíticos the e te, respectivamente, embasam a análise para a faixa I como um uso neutralizado de ambas as formas. No gráfico a seguir, podem-se visualizar melhor os resultados: 
Gráfico 2: Distribuição (\%) por faixa etária dos clíticos te e lhe na representação das formas objetivas para referenciar o interlocutor

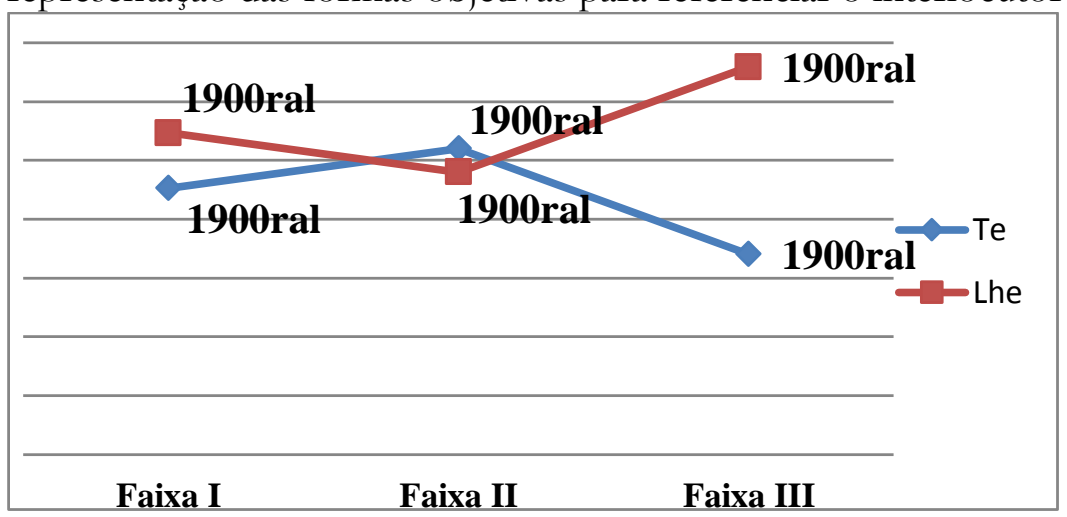

Fonte: Elaborado pela pesquisadora.

Embora seja possível a correlação entre os paradigmas de segunda e terceira pessoa para as formas te e lhe para o $\mathrm{PB}$ em geral, o falante feirense opta por preencher o objeto de referência ao interlocutor com o clítico lhe. Isso confirma a hipótese do estudo, sendo a variação entre os clíticos para referenciar o interlocutor também presente na fala de Feira de Santana. Os estudos do fenômeno em Salvador mostraram maior uso, também, dessa forma de preenchimento do objeto pelos mais velhos, outro dado confirmado igualmente na amostra deste estudo, visto que os feirenses com idade acima de 65 anos fazem maior uso do clítico.

A hipótese possível para analisarmos o resultado parte da noção de tratamento antecedente dada ao clítico em questão. Segundo Almeida (2014, p. 199) esse clítico possui traço de [+ formal] em oposição ao clítico te [-formal] "[...] o falante [...] revela maior probabilidade de optar por preencher a posição do objeto com o lhe quando o tratamento antecedente for representado por senhor/senhora [+formal] e você, dado o traço [+formalidade/cortesia]". Nesse caso, em comparação com a faixa II, a influência ao menor uso do clítico diz respeito à tendência à informalidade na sociedade contemporânea, sendo isso reflexo de uma "cultura global que quer ser sempre mais jovem" (MENDES, 1998, p. 138). Os mais jovens, tendem ao uso de ambas as formas, em um paradoxo de the [+formal] entre te [-formal], estabelecendo uma neutralidade no uso das formas.

O gráfico reproduz um padrão descente de uso do clítico the, com proporção decrescente quando menor for a faixa etária. Isso sugere que a comunidade de Feira de Santana possui uma tendência que caminha para um uso estável das duas formas clíticas para representação do objeto referenciado ao interlocutor.

\subsection{A ESCOLARIDADE DOS INFORMANTES}

O segundo grupo considerado relevante na amostra foi escolaridade dos informantes. A terminologia conferida ao termo popular e culto parte de estudos anteriores sobre a formação polarizada do PB, na qual divergem as duas vertentes, 
(MATTOS E SILVA, 2004). Dessa maneira, considera-se popular os informantes com pouca escolaridade, no caso da amostra coletada os falantes tinham o ensino fundamental incompleto, sendo a escolaridade máxima até o $7^{\circ}$ ano (antiga sexta série). Os falantes cultos são os feirenses com nível superior completo, preferencialmente sem formação acadêmica na área de Letras. Os dados resultantes desse grupo na amostra estão apresentados na tabela 02, com as devidas ocorrências e os pesos relativos correspondente.

Tabela 02: Atuação da variável escolaridade no uso dos clíticos te e lhe como representantes do objeto na forma de segunda pessoa. Significância: 0.008

\begin{tabular}{|c|c|c|c|c|c|c|}
\hline & \multicolumn{3}{|c|}{$\mathrm{Te}$} & \multicolumn{3}{|c|}{ Lhe } \\
\hline & Apl./Total & $\%$ & P.R & Apl./Total & $\%$ & P.R \\
\hline Popular & $(100 / 252)$ & $39,7 \%$ & 0.44 & $(152 / 252)$ & $60,3 \%$ & 0.54 \\
\hline Culto & $(115 / 231)$ & $49,8 \%$ & 0.55 & $(116 / 231)$ & $50,2 \%$ & 0.44 \\
\hline TOTAL & $(215 / 483)$ & $44,5 \%$ & - & $(268 / 483)$ & $55,5 \%$ & - \\
\hline
\end{tabular}

Fonte: Elaborado pela pesquisadora.

Comumente a escola tem atuado como uma tônica indispensável para os estudos de cunho variacionista, pois a incidência da escolaridade condiciona o uso de formas mais conservadoras, prescritas pela gramática tradicional, ensino priorizado em sala de aula. Segundo a G.T, o clítico the deve referenciar a terceira pessoa do discurso, no entanto, os dados da pesquisa mostram que os falantes feirenses que possuem um nível maior de escolaridade, os cultos, fazem uso variável do clítico the para referenciar a segunda pessoa, opondo-se ao que dita a tradição.

Os resultados para o uso variável do lhe entre os falantes de nível superior é de $50,2 \%$ (116/231), porém, o peso relativo é de 0.44 , sendo ainda maior o peso relativo quanto ao uso do te, com frequência de 49,8\% (115/231), equilibrados para esse fator. A hipótese para o uso equilibrado entre as variantes deve-se ao fato de ser o the um pronome-objeto de avaliação não negativa pelos falantes, possuindo marca de inovação menos perceptível. Os falantes com menor escolaridade, da vertente popular, apreenderam as maiores frequências para o uso do clítico the, com 60,3\% (152/252) e te, com 39,7\% (100/252), cujos pesos relativos são de 0.54 e 0.44 , respectivamente; próximos ao ponto neutro, com leve favorecimento ao uso do lhe.

\section{CONSIDERAÇÔES FINAIS}

Os dados resultantes selecionaram os grupos de fatores faixa etária e escolaridade dos informantes como fatores extralinguísticos condicionantes ao uso da regra variável. Sobre a faixa etária, os informantes acima de 65 anos (faixa III) fazem maior uso do 
clítico the para referenciarem o interlocutor, com frequência de 65,9\% (91/138), peso relativo favorável, em 0.60. A hipótese ao uso do clítico pelos mais velhos se aplica quando conferimos ao clítico lhe o traço de [+formal], propício ao perfil social dos indivíduos dessa faixa etária. Os mais jovens neutralizam o uso entre ambos os clíticos, tendo o the $54,7 \%$ (94/172) peso relativo de 0.50 e te $(78 / 172) 45,3 \%$, com peso relativo de 0.51. Há, nessa faixa etária, um uso estável entre ambas as formas para referenciar a segunda pessoa.

Ao segundo grupo, escolaridade dos informantes, confirma a hipótese de que os falantes com menor escolaridade (popular) fazem maior uso do clítico não padrão, com $60,0 \%$ (152/252), peso relativo de 0.54. A escola é uma tônica importante nesse grupo de fatores, visto que a instrução das formas padronizadas pela gramática normativa confere ao ensino superior, uso mais expressivo das formas canônicas (BAGNO, 2011). Contudo, o uso da forma inovadora ocorre, também, na fala dos mais escolarizados, visto que o peso de 0.44 aos falantes cultos da amostra confere um número próximo à zona de neutralização.

Tal resultado, mesmo que significativo, não confere, nesta amostragem, uma hipótese categórica de que o clítico lhe, mesmo sendo alternado com o clítico te, forma canônica para se referir ao interlocutor, possibilite ou não à variação, uma possível mudança linguística na comunidade, pois os dados aqui são apresentados em percentuais $(\%)$, sendo valores brutos. Sobre esse resultado para amostras em tempo aparente, Tarallo (1997, p. 65-66) explica:

Se você observar os índices apresentados para as outras variáveis, notará que não há menor possibilidade de mudança em progresso: trata-se simplesmente de casos de variáveis estáveis, em relação de contemporização [...] Se, por outro lado, o uso da variante mais inovadora for mais frequente entre os jovens, decrescendo em relação à idade dos outros informantes, você terá presenciado um situação de mudança em progresso [...].

No caso da amostra de Feira de Santana, aos resultados são explicados, visto que os índices de maior uso da variante mais inovadora, lhe, é mais frequente pelos mais velhos. Os mais jovens fazem um uso balanceado entre as duas formas referenciadas.

\section{REFERÊNCIAS}

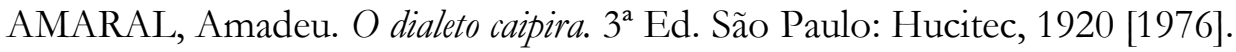

ALMEIDA, Gilce de Santana. Prescrição gramatical e uso: o caso do pronome lhe no português brasileiro. Anais do XV congresso Nacional de linguística e Filologia, vol. XV, $\mathrm{N}^{\circ}$, t. 3. Rio de Janeiro: ClFEFiL, 2011, p. 2398-2408. Disponível em: http://www.filologia.org.br/xv_cnlf/tomo_3/204.pdf. Acesso em: 19. jul. 2015, às 01: 21.

ALMEIDA, Gilce de Santana. Quem te viu quem lhe vê: a expressão do objeto acusativo de referência a segunda pessoa na fala de Salvador. Dissertação de mestrado em Linguística. Salvador: UFBA / Instituto de Letras, mimeo, 2009. 
ALMEIDA, Gilce de Santana. Uso variável dos pronomes-objeto na expressão do dativo e acusativo de segunda pessoa em Santo Antônio de Jesus- $B A$. Tese de doutorado. Universidade Federal da Bahia. Programa em Pós-Graduação em Língua e Cultura, Salvador: 2014.

BAGNO, Marcos. O preconceito linguístico. Ed. 54. São Paulo: Loyola, 2011.

GALVES, Charlotte. A sintaxe do português brasileiro. In: Ensaios de Linguística, n. 13, 1987. p.31-50.

GALVES, Charlotte. O enfraquecimento da concordância no português brasileiro. In: KATO, Mary; ROBERTS, Ian. (Org.). Português brasileiro: uma viagem diacrônica. Campinas: Editora da Unicamp, 1993. cap. XII, p. 387-406.

LABOV, William. Padrões sociolinguísticos. Tradução de Marcos Bagno; Ma. Marta Pereira Scherre; Caroline Cardoso. São Paulo, Parábola, 1972 [2008].

LOPES, Célia Regina dos Santos; CAVALCANTE, Silvia Regina de Oliveira. A cronologia do Voceamento no português brasileiro: expansão de você-sujeito e retenção do clítico-te. In: Linguística. Vol. 25, junho 2011, p. 30-65.

LUCAS, Elaine Mesquita. Transitividade variável em verbos monotransitivos e o uso inovador do clítico the no português do Brasil. Dissertação de mestrado em Linguística. Brasília: Universidade de Brasília, 2008.

LUCCHESI, Dante; MELLO, Camila. A alternância dativo. In: LUCCHESI, Dante.; RIBEIRO, Ilza.; BAXTER, Alan. O português afro-brasileiro. Salvador: Editora da UFBA, 2009, p. 427-456.

MATTOS E SILVA, Rosa Virgínia. Para a história do português culto e popular brasileiro: sugestões para uma pauta de pesquisa. In: ALKMIM, Tânia Maria. Para a história do português brasileiro: novos estudos. São Paulo: Humanitas/FFCHL/USP: FAPESP, v. 2, 2002, p. 443-464.

MATTOS E SILVA, Rosa Virgínia. De fontes sócio-históricas para a sóciohistórialingüística do Brasil: em busca de indícios. In: MATTOS E SILVA, Rosa Virgínia. Para a história do português brasileiro. Volume II: Primeiros estudos. Tomo 2. São Paulo: Humanitas, 2001, p. 275-301.

MATTOS E SILVA, Rosa Virgínia. Ensaios para uma sócio-história do português brasileiro. São Paulo: Parábola Editora, 2004.

MATTOS E SILVA, Rosa Virgínia. Ouvir o inaudivel. São Paulo: Humanitas/FFCHL/USP. FAPESP, 2008, v. II, tomo II, p.257-302.

MATTOS E SILVA, Rosa Virgínia. O português são dois: novas fronteiras, velhos problemas. São Paulo: Parábola Editorial, 2004.

MARROQUIM, Mário. A língua do nordeste: Alagoas e Pernambuco. 2.ed. São Paulo: Companhia Editora Nacional, 1934 [1996].

MIRA MATEUS, Maria Helena. Se a língua é um factor de identificação cultural, como se compreende que a mesma língua identifique culturas diferentes? In: CARDOSO, Suzana.; MOTA, Jacyra.; MATTOS E SILVA, Rosa Virgínia. (Org.). Quinhentos anos de história linguística do Brasil. Salvador: Secretaria da Cultura e Turismo do Estado da Bahia, 2006. p. 63-80.

MENDES, Eliana Amarante de Mendonça. Você, o senhor ou o quê? Linguagem e Ensino. v. I, n. 1, p. 135-150, 1998. 
NASCENTES, Antenor. O linguajar carioca. $2^{\mathrm{a}}$ ed. Complemente refundida. Rio de Janeiro: Organização Simões, 1922.

OLIVEIRA, Marilza de. A perda da preposição a e a recategorização de lhe. Artigo publicado nos anais do GEL, 2003. Disponível em: http://www.fflch.usp.br/dlcv/lport/pdf/maril008.pdf. Acesso em: 19. jul. 2015.

OLIVEIRA, Marilza de. O futuro da língua portuguesa ontem e hoje: variação e mudança. Tese de doutorado em Linguística - Universidade Federal do Rio de Janeiro. Rio de Janeiro, 2006. Disponível em: http://www.letras.ufrj.br/posverna/doutorado/OliveiraJM.pdf; Acesso em: 17. Jan. 2016.

RAMOS, Conceição de Maria Araújo. O clítico de $3^{a}$ pessoa: um estudo comparativo português brasileiro / espanhol penisular. Tese de doutorado em Linguística Universidade Federal de Alagoas. Maceió, 1999.

SILVA, Deyse Edberg Ribeiro.; ALMEIDA, Norma Lucia Fernandes de. Lheísmo no português brasileiro: examinando o português falado em Feira de Santana. In: XVI Seminário de Iniciação Cientifica da UEFS: sustentabilidade, economia verde e erradicação da pobreza, 2012, Feira de Santana. Anais e resumos [do] XVI Seminário de Iniciação Científica da UEFS. Feira de Santana: Universidade Estadual de Feira de Santana, 2012.

SILVA, Deyse Edberg Ribeiro.; ALMEIDA, Norma Lucia Fernandes de. A alternância do pronome oblíquo lhe como objeto acusativo na fala popular e culta: anotações sobre caso de Feira de Santana. In: III Encontro de Sociolinguística: Salvador, sob o olhar da Sociolinguística. Feira de Santana: UEFS Editora, 2013. v. 1 v. p. 7-166.

SILVA, Deyse Edberg Ribeiro. A variação na representação do objeto dativo e acusativo em Feira de Santana. Dissertação de mestrado em Linguística - Feira de Santana, 2016.

TARALLO, Fernando. Sobre a alegada origem crioula do português brasileiro: mudanças sintáticas aleatória. In: ROBERTS, Ian; KATO, Mary (Org.). Português brasileiro: uma viagem diacrônica, Campinas: Editora da Unicamp, 1993. p. 35-68.

TARALlO, Fernando. A pesquisa Sociolinguística. 5. Ed. São Paulo: Ática, 1997.

WEINREICH, Uriel; LABOV, William; HERZOG, Marvin. Fundamentos empíricos para uma teoria da mudança linguistica. Tradução de Marcos Bagno. São Paulo: Parábola Editorial, 1968 [2008].

Recebido em: 15/06/2018

Aprovado em: 23/08/2018

Publicado em: 31/12/2018 